lay down as a rule, that tincture of iodine ought not to be prescribed in a mixture containing either of the above-named alkaloids. Probably a similar reaction would take place with other alkaloids, but of these $I$ have no experience.

Another question of practical importance arises out of this observation: May not a dilute solution of iodine be advantageously given as an antidote in cases of poisoning by strych. nine? Neither in Dr. Taylor's work on Poisons, nor in any other work which I have bad the opportunity of consulting, do $I$ find the slightest reference to iodine as an antidote to strychnine; but if a drachm of the tincture of iodine of the Pharmacopceia suffices to precipitate and render insoluble no less than a grain and a half of strychnine (three drachms of the liquor strychniæ), it is difficult to resist the conclusion that, if cautiously administered, iodine may prove a valuable and efficient remedy in cases of poisoning by strychnine.

Manchester-square, March, 1868.

\section{GUNSHOT WOUND IN THE HEAD.}

\section{INJURY TO BRAIN WITHOUT SEVERE SYMPTOMS;} RECOVERY.

By F. J. GRAY, EsQ.

ON November 18th I was called to J. W-, aged twentyone, who had been accidentally shot by a bullet from a revolver. On examination, I found that the bullet had entered an inch above the lobe of the left ear, from before upwards and backwards; blood was oozing from the wound and ear; he was very faint, but not totally insensible. I enlarged the opening, and found part of the bullet (which I extracted) wedged in the hole of the bone; it appeared cut off by the edge of the bone. I also extracted six pieces of bone which were in the skull, and passed the probe in search of the other portion of bullet. 'The probe appeared by its own weight to go two inches into the brain, and also two inches under the skull backwards. I considered, with Messrs. Taunton and Balderon, surgeons, who were with me, that the symptoms did not warrant my further searching for the remaining portion of bone. When extracting a small piece of bone, a gush of dark grumous blood came, evidently from rupture of the lateral sinus. His pupils acted but sluggishly. I applied wet lint to the wound, irrigation, and afterwards ice-bags to his head. He slept for several hours, and when roused he was in a semiconscious state. Had great difficulty to swallow a teaspoonful of water; but shortly afterwards was very sick, vomiting his supper, which he had had just before the accident. During the vomiting a great gush of blood came from the skull. His feet being cold, hot bricks were applied; no paralysis. Twelve hours after the accident he had much recovered from the semi-conscious state, and was able to swallow; had a little milk and water. Passed the catheter; drew off a pint of urine. Gave three grains of calomel, and a saline draught an hour afterwards, which he vomited, when another gush of blood came from the skull. Gave him a mixture of sulphate of magnesia, nitrate of potash, tartar emetic, and tincture of hyoscyamus, every four hours. His pulse was feeble, and intermitting between 60 and 67 . He took with difficulty a few teaspoonfuls of milk and water. The wound having begun to heal, I broke up the adhesions, gave him three grains of calomel, and ordered saline draught in the morning.

Nov. 20th. - Had a comfortahle night; bowels not open; vomited saline draught. Gave him five grains of calomel, half a grain of jalap, afterwards two drops of croton oil ; bowels open. Opened the wound, and applied oiled silk.

2lst. - Much improved; good night; not so drowsy; pulse quiet and regular; sat on the edge of the bed contrary to orders, and passed a large quantity of urine. Diet : milk and water, blancmange, and weak broth. Mixture continued; linseed-meal poultice to the wound.

22nd.-Doing well ; bowels not open.

23rd.-Complained of heat in the head; tongue yellow, and rather brown in the centre; bowels not open; bowels not been opened for several days (having been wrongly informed the day before). Gave him calomel and saline draught; the tongue being more brown and dry, and pulse feeble, I stopped the tincture of antimony, and substituted ammonia. In the evening, the bowels not having been opened, an enema was given, after which a large quantity of offensive fæces came away, which relieved him very much. Beef-tea, broth, and jelly being given, the tongue gradually became moist and clean.

24th. - Much better; no pain or giddiness in the head even when out on stool, to which he gets up contrary to orders.

Dec. 1st. - Much better; has had meat several times during the week; has sat up in easy chair several times; walked fifty yards to the cab to go home.

3rd.- No ill effects from journey home ; wound gradually granulating up; dressed with calamine ointment.

12th. - Wound healed up; goes out for a walk.

Jan. 1ŏth, 1868. - Has gone to work, he being an apprentice to an iron moulder and fitter, and resumed his place as a member of the band, and plays a brass instrument (of course, contrary to my advice).

The case, being a serious one, has gone on from first to last well, although he has been a most obstinate patient, and would do very indiscreet things contrary to my orders, but apparently with impunity.

By the probe going direct into the brain with its own weight, my impression is that the remaining part of the bullet has gone into the brain-substance, although no severe symptoms have arisen, or has he ever complained of headache or giddiness. I cannot help thinking, however, that he will suffer from these symptoms.

Rugeley, March, 1868.

\section{ON A CASE OF TRIPLETS.}

\section{BY ALEXANDER CRICHTON, L.R.C.P., \&c.}

As cases of triplets are extremely rare, they generally excite a certain amount of interest amongst professional men. The following notes of a case which occurred to me the other day may, perhaps, be worthy of a place in THE LANCET.

On the 18th February, a young woman, Margaret $\mathrm{C}-$ _- aged twenty-five, called on me and complained of pain in the back and down the limbs. As she had not been able to sleep from it for a few nights, I gave her a dose of tincture of opium, and promised to call next day, which I did, and found the pain abated. She told me she was in the family way, and, judging from her appearance, $I$ concluded she was at her full time, as the distension of the abdomen extended to the sternum. She, however, told me that she was not more than five months, and this, together with the extreme distension and tensity of the abdomen, led me to expect something abnormal; nor was I mistaken, for about six o'clock on the morning of the $22 \mathrm{nd}$, I was rung up to see this girl. I got there about half an hour afterwards, and found her sitting in bed, and between the legs lay a dead foetus of five months. I tied the cord and removed the child, and, after waiting a time, I found the abdomen still very much distended, the placenta firm, and no hæmorrhage. As no pains were recurring, I left a message to send for me if anything should occur, and, accordingly, about ten o'clock, I was again sent for. I returned and found the pains coming on regularly, and, finding symptoms of convulsions, I sent for Mr. Brown, with whose valuable assistance the labour was got over. The membranes ruptured about a quarter past ten, and the second child was born at half-past ten. After tying the cord, \&c., and waiting a little time finding that there was still another child, a dose of extract of ergot was given, and about twelve o'clock the next child was born enveloped in the membranes. Some difficulty was experienced in the birth of the last child on account of the placenta of the former children being impacted between the head of the child and the symphysis pubis ; but when this was overcome the placenta came away and the labour was over. There was very little hæmorrhage during the labour. Since the delivery she has had a slight attack of puerperal fever; but under the use of calomel and opium it has entirely subsided, and the patient is now well. I may add that the children were all females.

Mortlake. Mrarch i1th, 1868

Norty of ExGland Obstetrical Societry. - The annual meeting of this Society was held on the $\Pi$ th ult. at the College of Medicine, Newcastle-on-Tyne, when the following officers were elected :-President: Dr. Charles Gibson. Vice-presidents : Dr. Canney, Mr. T. C. Nesham, Mr. Russell, and Mr. Pyle. Committee : Drs. Banning, Denham, May, Messrs. Hope, Angus, and Ridley. Honorary Secretary : Dr. Ellis, Elswick West-terrace, Newcastle. 